\title{
Rancang Bangun Pengendali Dan Pengawasan Gas Amonia Pada Peternakan Ayam Berbasis Arduino Mega $2560 \mathrm{R3}$
}

\author{
Adi Sapto Raharjo ${ }^{1}$, Zaidir Jamal ${ }^{2}$ \\ Fakultas Ilmu komputer, Institut Informatika dan Bisnis Darmajaya \\ Jl. Z.A Pagar Alam No. 93, Bandar Lampung - Indonesia 35142 \\ Telp. (0721) 787214 Fax. (0721) 700261 \\ e-mail : adi.sapto.raharjo.1821211002@mail.darmajaya.ac.id, zaidir.jamal@darmajaya.ac.id
}

\section{Informasi Makalah}

Dikirim, 10 September 2019

Direvisi, 7 Desember 2019

Diterima, 11 Desember 2019

\section{Kata Kunci:}

Arduino Mega 2560 R3

$M Q-135$

DHT11

Blower

Heater

Aplikasi Monitoring.

\section{INTISARI}

Kadar gas amonia menjadi salah satu permasalahan yang kerap terjadi pada peternakan ayam. Ambang batas maksimal untuk kadar gas amonia yaitu 20 PPM (Part Per Million). Gas amonia muncul karena suhu yang tidak ideal pada kandang ayam. Diketahui bahwa suhu yang optimal pada kandang ayam dengan suhu $30^{\circ} \mathrm{C}$ (Celcius). Kenaikan kadar gas amonia yang tidak terekam juga merupakan permasalahan karena pemilik atau pengelola ayam tidak bisa mengontrol dan mengetahui apabila terjadi kenaikan kadar gas amonia. Dari permasalahan tersebut dirancangnya sistem pengendali kadar gas amonia dengan sensor MQ-135 sebagai sensor yang akan mendeteksi kadar gas amonia dan sensor DHT11 yang akan menjadi sensor yang mendeteksi suhu ruangan kandang ayam. Hasil pembacaan sensor gas dan sensor suhu diproses oleh arduino sebagai mikrokontroler. Sistem ini juga akan menyimpan kadar gas amonia yang terdeteksi oleh sensor MQ-135 kedalam database pada aplikasi monitoring tiap menit agar apabila terjadi kenaikan kadar gas amonia dapat terdeteksi kapan kenaikan kadar gas amonia terjadi. Keluaran dari sistem ini akan ditampilkan kadar gas amonia dan suhu ke layar LCD 16x4 serta mikrokontroler yang mengirimkan signal ke driver relay untuk menghidupkan blower apabila kadar amonia yang terdeteksi melebihi 20 PPM lalu mengeluarkan gas amonia ke luar kandang ayam dan menghidupkan heater apabila suhu yang terdeteksi kurang dari $30^{\circ} \mathrm{C}$ untuk mengendalikan suhu kandang ayam.

\section{ABSTRACT}

The increase of the level of Amonia was one of the problems in the chicken farms. The maximum threshold for the Amonia is 20 PPM (Part Per Million). The amonia arises because the temperature is not ideal in the chicken coops. The optimal temperature in the chicken coop should be $30^{\circ} \mathrm{C}$. The problem statement of this research was that there was the increase of the level of Amonia and it was not regarded as the problem because the owner or manager did not know 
Heater

Monitoring Aplication. and control the increase of the level of Amonia. To solve the problem, the Amonia control system was designed with MQ-135 sensor to detect the Amonia gas level. Moreover, the DHT11 sensor was used as the sensor to detect the chicken coop temperature. The scanning result of this gas sensor and temperature sensor was processed by Arduino as the microcontrollers. This system stored the Amonia detected by MQ-135 sensors into the database in a monitoring application in every minute. The increase of the level of Amonia was able to be detected as the increase of the level of Amonia occurred. The output of this system was in the form of the level of Amonia and temperature displayed through the $16 \times 4$ LCD. Moreover, the microcontroller sent the signal to the relay driver to turn on the blower if the detected Amonia exceeded 20 PPM which emitted the Amonia out of the chicken coop. The heater was turned on to control the temperature of the chicken coop if the detected temperature was less from $30^{\circ} \mathrm{C}$.

\section{Korespondensi Penulis:}

Adi Sapto Raharjo

Program Studi Sistem Komputer

Fakultas Ilmu Komputer

Jl. Z.A Pagar Alam No. 93, Bandar Lampung - Indonesia 35142

Email: adi.sapto.raharjo.1821211002@mail.darmajaya.ac.id

\section{PENDAHULUAN}

Indonesia merupakan negara kepulauan yang memiliki cakupan wilayah yang luas sering disebut sebagai negara agraria atau negara yang penduduknya sebagian besar bekerja disektor pertanian. Selain bertani, kebanyakan masyarakat indonesia juga berusaha disektor peternakan. Usaha peternakan yang dilakukan oleh masyarakat diantaranya peternakan ayam, peternakan peternakaan sapi dan peternakan burung puyuh. Di provinsi Lampung, populasi ayam pedaging meningkat setiap tahunnya, hingga tahun 2016 mencapai 34.264.909 ekor [1].

Seiring dengan banyaknya pengusaha peternakan ayam di Indonesia, maka salah satu dampak dari usaha tersebut terhadap lingkungan sekitar adalah berupa bau yang dikeluarkan oleh kotoran ayam. Bau kotoran ayam berupa kandungan gas amonia, yang merupakan salah satu gas pencemar udara yang dapat dihasilkan dari penguraian senyawa organik oleh mikroorganisme [2].

Penyebab gas amonia adalah suhu yang relatif rendah yang dipengaruhi oleh keadaan kelembapan dalam kandang peternakan dan lingkungan luar peternakan. Batasan dari kadar amonia untuk lingkungan peternakan yaitu sebesar $20 \mathrm{ppm}$ (part per million)[3]. Apabila melampaui dari batasan yang tersebut dapat menyebabkan iritasi pada mata dan tenggorokan hewan ternak bahkan bisa menyebabkan kematian pada ayam[3]. Hal tersebut akan merugikan ekonomi para peternak ayam.

Berdasarkan permasalahan tersebut, maka dibutuhkan suatu sistem yang dapat memonitor gas amonia dengan menggunakan sensor gas amonia lalu ditambahkan sensor DHT11 yang digunakan untuk memonitoring suhu dan dibutuhkan suatu program berbentuk desktop application yang digunakan untuk mengambil data dari sensor gas amonia dan menyimpan data tersebut kedalam database $S Q L$ lalu menampilan dalam bentuk laporan yang berisi nilai kadar gas amonia serta kapan terdeteksinya kadar gas amonia. 


\section{METODE}

Penelitian ini dilaksanakan di laboratorium elektronika Institut Informatika dan Bisnis Darmajaya. Observasi dilakukan di kecamatan metro kibang, kabupaten lampung timur. Observasi dilakukan untuk mendapatkan informasi berkatian dengan data data yang diperlukan peternak di lokasi tersebut. Proses penelitian ditunjukan pada gambar 1 berikut.

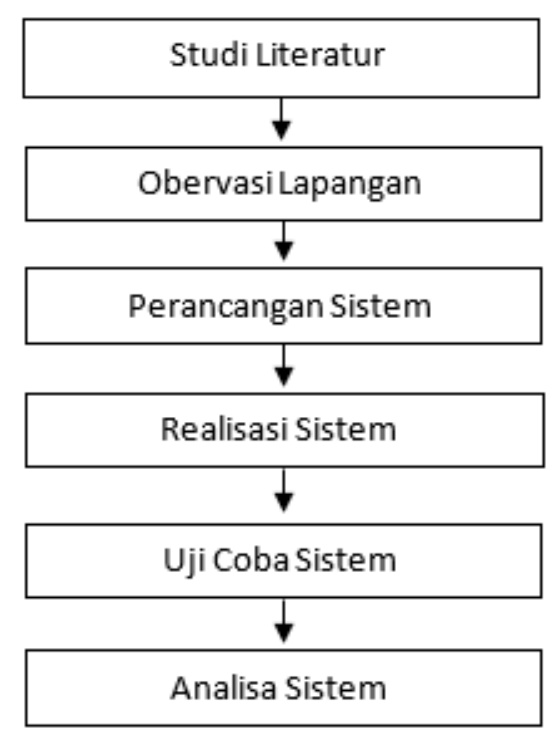

Gambar 1. Alur Pengembangan Sistem

Penjelasan:

\section{Studi Literatur}

Pada proses ini penulis mencari bahan penulisan makalah ilmiah jurnal penelitian yang diperoleh dari buku, jurnal dan website yang terkait dengan rancang bangun sistem monitoring gas amonia pada peternakan ayam berbasis arduino mega 2560 r3.

\section{Observasi Lapangan}

Observasi lapangan dilakukan guna mendapatkan data tentang pentingnya penggunaan laporan untuk pendataan kadar amonia pada kandang ayam. Observasi ini dilakukan dengan mengunjungi para peternak dan wawancara langsung secara tertulis.

\section{Perancangan Sistem}

Perancangan sistem yang digunakan terkait dengan rancang bangun sistem monitoring gas amonia pada peternakan ayam berbasis arduino mega 2560 r3. Perancangan ini terbagi menjadi 2 macam, yaitu perancangan perangkat keras dan perancangan perangkat lunak.

\section{Realisasi Sistem}

Pada tahapan ini rancangan sistem perangkat keras dan perancangan perangkat lunak direalisasikan guna mendapatkan hasil penelitian. Realisasi pada metode ini dibagi juga menjadi 2 macam, yaitu realisasi perangkat keras dan realisasi perangkat lunak. Realisasi perangkat keras dilakukan dengan menyatukan bagian-bagian komponen menjadi sistem yang saling terintergrasi. Realisasi pada perangkat lunak dilakukan dengan mengaplikasikan kode program untuk mikrokontroler dengan menggunakan arduino IDE dan kode program untuk aplikasi monitoring dengan mengunakan lazarus.

\section{Uji Coba Sistem}

Setelah direalisasikan, dilakukan uji coba masing-masing bagian keseluruhan sistem. Uji coba sistem ini dilakukan diseluruh bagian pada perangkat keras. Pengujian perangkat lunak juga dilakukan dengan menguji instruksi pada arduino apakah sudah sesuai dengan kode program dan juga menguji program monitoring yang direalisasikan agar sesuai dengan instruksi pada kode program.

\section{Analisa Sistem}

Tahapan analisa untuk mengetahui bagaimana kinerja dari sistem. Analisa dilakukan setelah tahapan uji coba dan mensimulasikan aplikasi monitoring pada komputer dengan menghubungkan mikrokontroler untuk mendeteksi kadar gas amonia. 


\subsection{Perancangan Blok Diagram Perangkat Keras}

Perancangan sistem monitoring gas amonia pada peternakan ayam berbasis arduino mega $2560 \mathrm{r} 3$ ini meliputi perancangan perangkat keras dan perangkat lunak. Sistem tersebut dapat memberikan informasi mengenai status kadar gas amonia beserta suhu yang terukur. Adapun blok diagram dari alat pengendali dan pengawasan gas amonia pada peternakan ayam dapat dilihat pada gambar berikut.

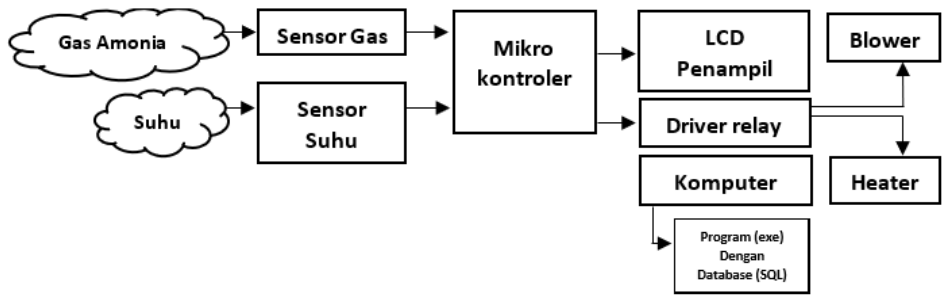

Gambar 2. Blok Diagram Perangkat Keras

Sistem Monitoring dan pengendali menggunakan mikrokontroler Arduino Mega 2560 R3 untuk menerima input dari sensor gas dengan menggunakan sensor MQ-135 sebagai pendeteksi gas amonia dan sensor DHT11 sebagai sensor suhu pada kandang ayam. Gas amonia yang terdeteksi oleh sensor MQ-135 akan diproses oleh mikrokontroler Arduino Mega 2560 R3 yang akan mengirim sinyal high (1) ke driver relay untuk menghidupkan blower. Sensor suhu DHT-11 akan diproses oleh mikrokontroler Arduino Mega 2560 R3 yang juga mengirimkan sinyal high (1) ke driver relay untuk menghidupkan heater. Mikrokontroler arduino mega $2560 \mathrm{r} 3$ memproses data yang diterima dari input sensor yang akan ditampilkan pada penampil layar yaitu LCD 16x4 serta program GUI(.exe). yang menampilkan hasil deteksi kadar gas amonia dan otomatis menyimpan dalam database $S Q L$ yang terdapat pada program dalam durasi per-menit.

\subsection{Perancangan Flowchart dan Algoritma}

Perancangan flowchart ini dibuat bertujuan untuk mempermudah dalam pembuatan program, karena di dalam flowchart terdapat ilustrasi logika program yang akan dibuat. Berikut adalah flowchart pada perangkat keras seperti pada gambar 3.

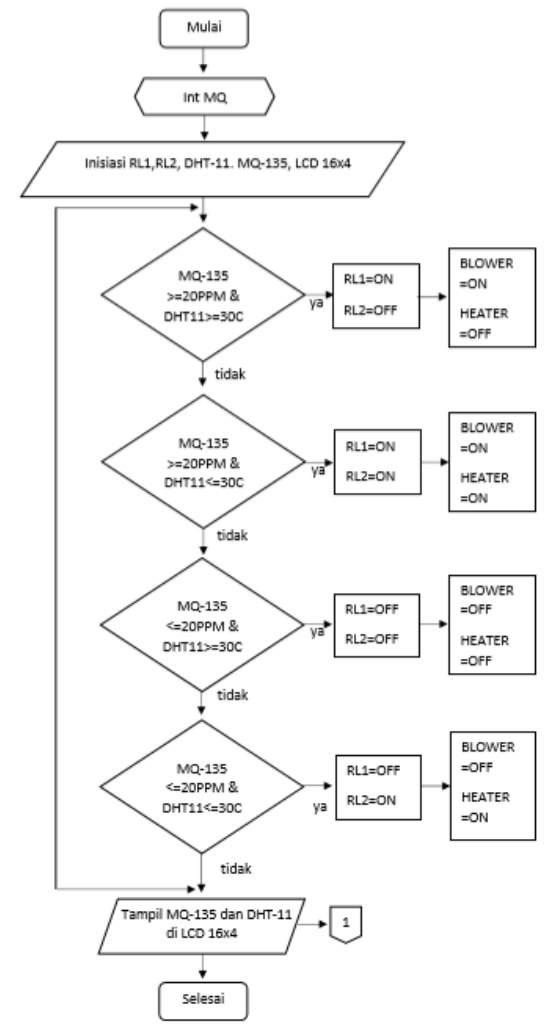

Gambar 3. Flowchart perangkat keras 
Penjelasan dari flowchart adalah sebagai berikut :

a. Langkah pertama adalah inisiasi port pada arduino uno yang akan digunakan.

b. Melakukan inisiasi variabel yang digunakan untuk program.

c. Sensor hidup dan siap untuk digunakan untuk mendeteksi adanya masukan data dari sensor MQ-135 maupun dari sensor DHT-1.

d. Memilih kondisi yang pertama, apabila sensor MQ-135 mendeteksi kadar amonia melebihi 20 ppm dan DHT11 lebih dari $30^{\circ}$ celcius, jika memenuhi kondisi, maka akan mengirimkan data ke arduino untuk mengoperasikan relay 1 untuk menghidupkan blower dan relay 2 untuk mematikan heater. Jika tidak memenuhi kondisi yang pertama, maka akan memilih kondisi yang kedua yaitu apabila sensor MQ-135 mendeteksi kadar amonia lebih dari 20 ppm dan DHT-11 mendeteksi kelembapan dan suhu dengan acuan suhu kurang dari dari $30^{\circ}$ celcius. Apabila memenuhi maka akan mengirimkan data ke arduino untuk mengoperasikan relay 1 dan relay 2 untuk menghidupkan blower dan heater. Jika tidak memenuhi kondisi yang kedua, maka akan memilih kondisi yang ketiga yaitu apabila sensor MQ-135 mendeteksi kadar amonia kurang dari 20ppm dan DHT-11 mendeteksi kelembapan dan suhu dengan acuan suhu lebih dari $30^{\circ}$ celcius. Apabila memenuhi maka akan mengirimkan data ke arduino untuk mengoperasikan relay 1 dan relay 2 untuk mematikan blower dan blower. Jika tidak memenuhi kondisi yang ketiga, maka akan memilih kondisi yang ke-empat yaitu apabila sensor MQ-135 mendeteksi kadar amonia kurang dari 20 ppm dan DHT-11 mendeteksi kelembapan dan suhu dengan acuan suhu kurang dari dari $30^{\circ}$ celcius. Apabila memenuhi maka akan mengirimkan data ke arduino untuk mengoperasikan kedua relay 1 untuk mematikan blower dan relay 2 untuk menhidupkan heater. Berikut flowchart pada program monitoring seperti pada gambar 4 .

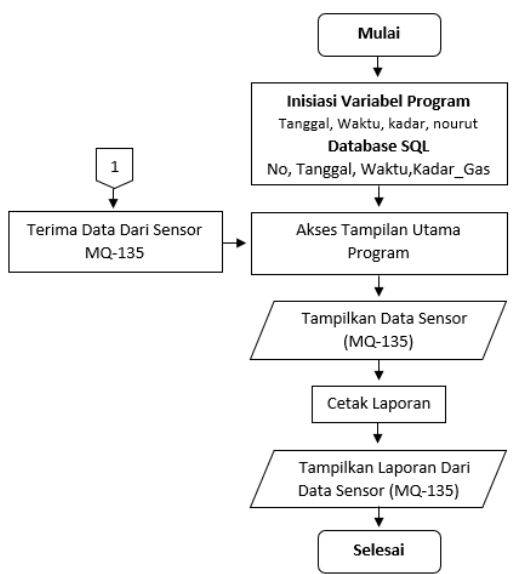

Gambar 4. flowchart program monitoring desktop

\subsection{Perancangan Desain Tampilan Program Monitoring}

Perancangan desain tampilan program monitoring berbasis desktop ini menggunakan IDE Lazarus dengan bahasa pemrograman Pascal. Dengan program ini peternak dapat melihat status kadar gas amonia dan suhu pada kandang ayam secara realtime serta bisa mengunduh data dari sistem yang dipasang pada peternakan. Perancangan tampilan program monitoring akan dibuat seperti pada gambar 5, 6, dan 7 .

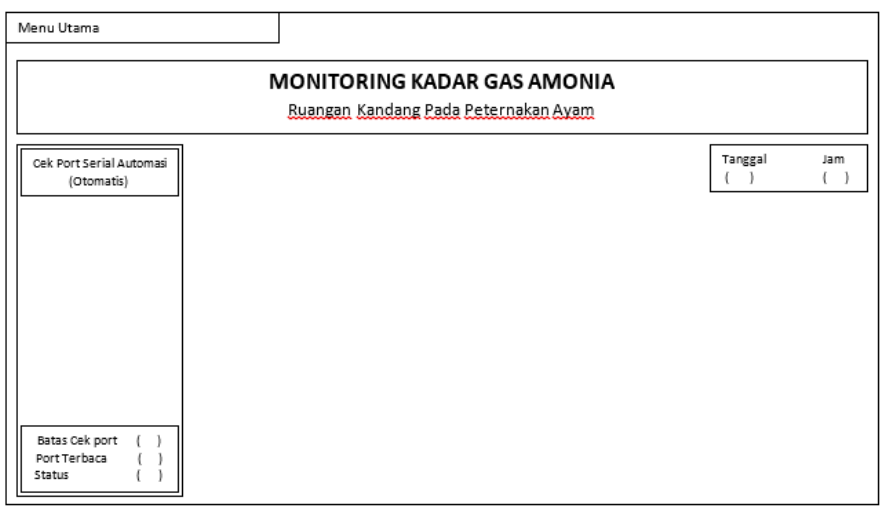

Gambar 5. Menu utama program monitoring 


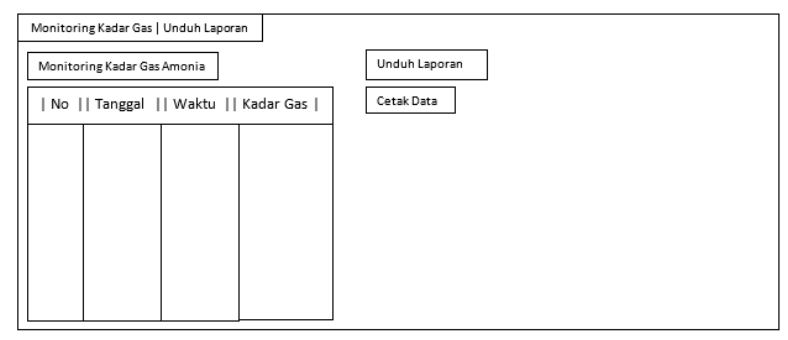

Gambar 6. Menu monitoring kadar gas | unduh laporan

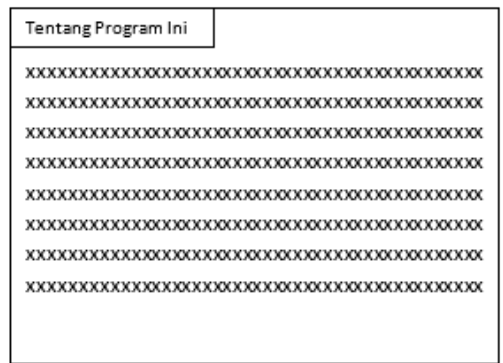

Gambar 7. Menu tentang program ini

\section{HASIL DAN PEMBAHASAN}

\subsection{Hasil Realisasi Perangkat Keras}

Hasil realisasi perangkat keras merupakan tahapan dari setelah tahapan perancangan sistem dilakukan. Dalam tahap ini seluruh komponen dipasang sesuai dengan perancangan sistem yang telah dibuat. Realisasi perangkat keras dapat dilihat pada gambar berikut.

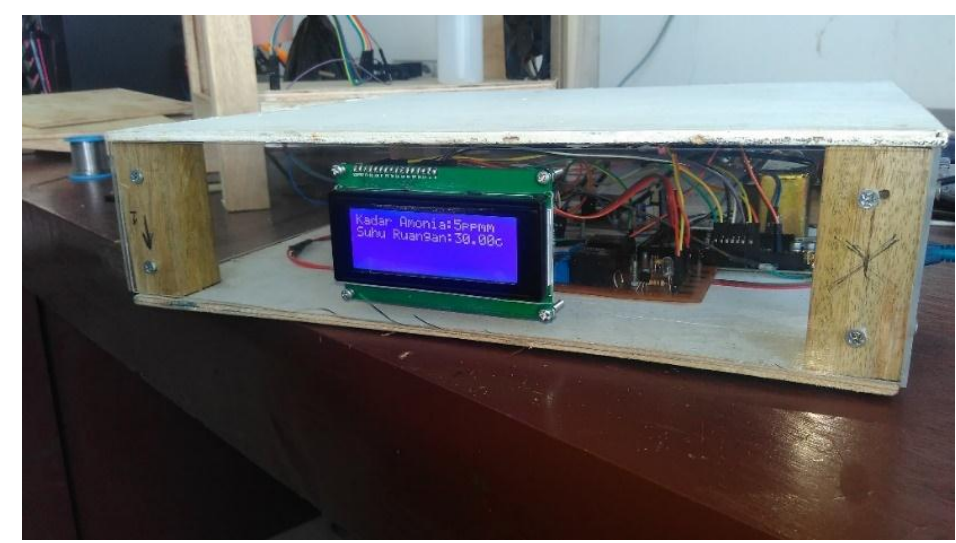

Gambar 8. Hasil Realisasi perangkat keras (tampilan depan)

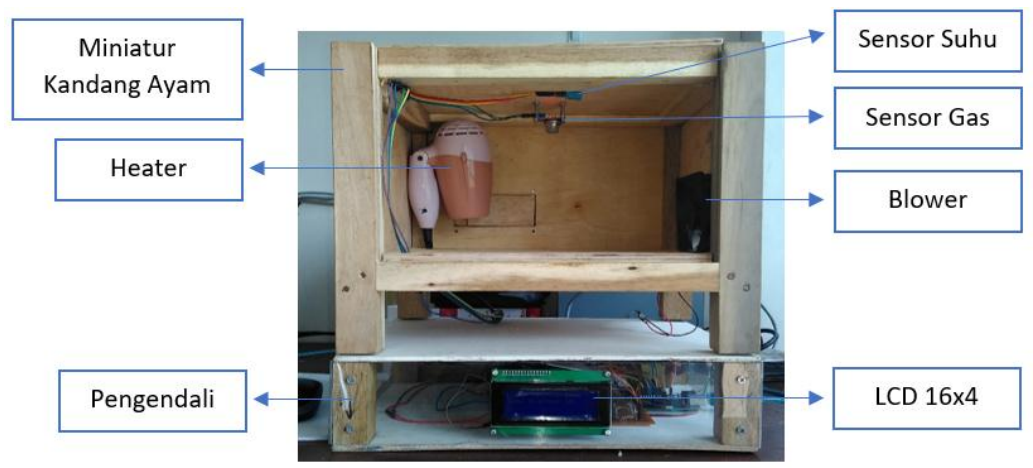

Gambar 9. Hasil Realisasi perangkat keras (tampilan keseluruhan) 


\subsection{Hasil Realisasi Perangkat Lunak}

Sistem monitoring gas amonia pada peternakan ayam berbasis arduino mega $2560 \mathrm{r} 3$ ini dibuat menggunakan Software berbasis desktop aplikasi yaitu Lazarus. Lazarus ini menggunakan sistem pemrograman berorientasi objek. Tampilan desain monitoring ditampilkan pada gambar berikut.

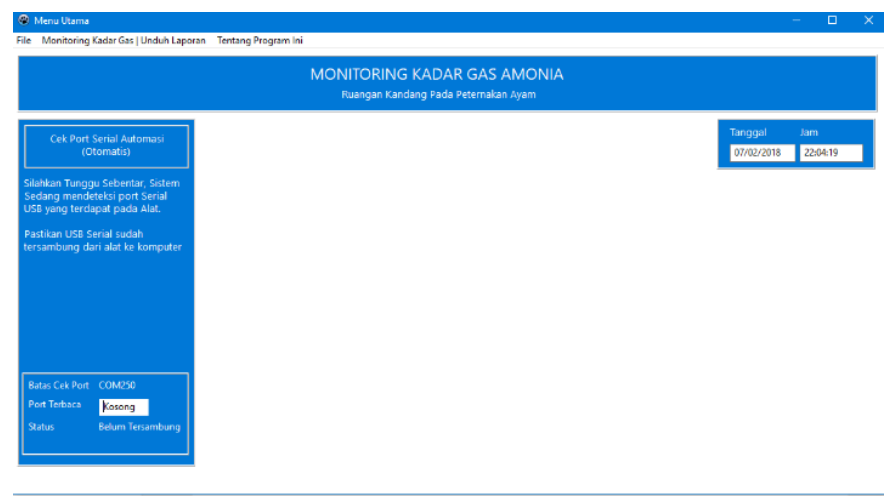

Gambar 10. Tampilan desain aplikasi

\subsection{Hasil Uji Keseluruhan Perangkat}

Hasil uji keseluruhan perangkat dibawah ini dilakukan dengan menguji respon dari pendeteksian gas amonia dan suhu yang terdeteksi oleh sensor gas amonia MQ-137 dan sensor suhu DHT11. Hasil uji ini juga menghasilkan output berupa status on/off pada akuator exshaus dan heater yang ada pada perangkat, hasil uji keseluruhan perangkat akan ditampilkan pada tabel 1 dibawah ini. Data dari sensor gas amonia MQ-137 juga disimpan pada Menu Monitoring Gas yang ada pada program Monitoring Kadar Gas Amonia.

Tabel 1. Hasil Uji Keseluruhan Perangkat

\begin{tabular}{|c|c|c|c|c|c|c|}
\hline $\begin{array}{c}\text { Menit } \\
\text { Uji } \\
\text { Coba }\end{array}$ & $\begin{array}{l}\text { Kadar Gas Amonia } \\
\text { yang terdeteksi Sensor } \\
\text { MQ-135 Dengan } \\
\text { Penambahan Cairan } \\
\text { Ammonium Hydroxide } \\
\text { (PPM) }\end{array}$ & $\begin{array}{l}\text { Suhu Terukur } \\
\text { yang terdeteksi } \\
\text { Sensor DHT11 } \\
\left({ }^{0} \mathrm{C}\right)\end{array}$ & $\begin{array}{l}\text { Kondisi } \\
\text { Blower }\end{array}$ & $\begin{array}{l}\text { Kondisi } \\
\text { Heater }\end{array}$ & $\begin{array}{c}\text { Tanggal } \\
\text { Simpan ke } \\
\text { Database }\end{array}$ & $\begin{array}{c}\text { Waktu } \\
\text { Simpan Ke } \\
\text { Database }\end{array}$ \\
\hline 1 & $\overline{5}$ & 25 & $\overline{\mathrm{OFF}}$ & $\overline{\mathrm{ON}}$ & $02-03-2018$ & 02:15:07 \\
\hline 2 & 9 & 26 & OFF & ON & 02-03-2018 & 02:16:07 \\
\hline 3 & 13 & 27 & OFF & ON & 02-03-2018 & 02:17:07 \\
\hline 3 & 15 & 28 & OFF & ON & 02-03-2018 & 02:18:07 \\
\hline 4 & 17 & 29 & OFF & ON & 02-03-2018 & 02:19:07 \\
\hline 5 & 20 & 30 & ON & OFF & 02-03-2018 & 02:20:07 \\
\hline 6 & 24 & 30 & ON & OFF & 02-03-2018 & 02:21:07 \\
\hline 7 & 21 & 30 & ON & OFF & 02-03-2018 & 02:22:07 \\
\hline 8 & 18 & 30 & OFF & OFF & 02-03-2018 & 02:23:07 \\
\hline 9 & 15 & 30 & OFF & OFF & 02-03-2018 & 02:24:07 \\
\hline 10 & 13 & 30 & OFF & OFF & 02-03-2018 & 02:25:07 \\
\hline
\end{tabular}

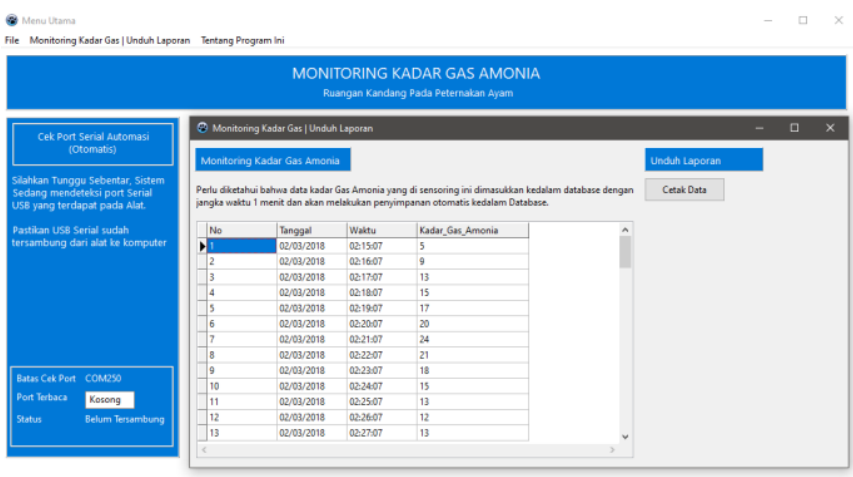

Gambar 11. Menu Monitoring Kadar Gas pada program Monitoring Kadar Gas Amonia (exe) 


\section{KESIMPULAN}

Berdasarkan penelitian yang telah dilakukan yang didalamnya dilakukan perancangan, hasil, pengujian dan analisa sistem yang telah dilakukan, dapat disimpulkan beberapa hal yang dilakukan sebagai berikut:

a. Modul sensor gas MQ-135 telah mendeteksi kenaikan kadar gas amonia dengan pengukuran hingga 30ppm menggunakan cairan Amonium Hydroxide. Kadar yang terukur pada sensor akan semakin tinggi apabila cairan Amonium Hydroxide masih berada disekitar sensor.

b. Modul sensor suhu DHT11 telah mendeteksi kenaikan kadar gas amonia dengan pengukuran hingga $30^{\circ} \mathrm{C}$ dapat mendeteksi suhu hingga $50^{\circ} \mathrm{C}$.

c. Data yang terdeteksi pada sensor MQ-135 akan disimpan didalam database pada aplikasi monitoring dengan durasi per 1 menit.

d. Driver relay dapat beroperasi pada tegangan $12 \mathrm{~V}$. Kondisi relay akan menjadi OFF (normaly close) apabila tegangan output dari pin mikrokontroler dibawah $5 \mathrm{~V}$. Apabila tegangan output mikrokontroler lebih dari $5 \mathrm{~V}$, kondisi relay akan menjadi ON (normaly open) dan akan mengalirkan tegangan ke blower/heater.

e. Sistem sudah bekerja sesuai dengan rancangan, yaitu informasi data yang didapatkan sesuai dengan data yang dikirimkan oleh perangkat keras.

f. Database $S Q L$ yang digunakan untuk menyimpan data dari sensor gas amonia pada mikrokontroler disimpan menggunakan program desktop monitoring kadar gas amonia (.exe).

g. Dengan adanya program desktop tersebut, pemilik peternakan bisa secara lansung membuka program dektop ini untuk memantau kenaikan gas amonia sebagai tolak ukur / acuan apabila terjadi kenaikan kadar gas amonia pada peternakan ayam.

\section{DAFTAR PUSTAKA}

[1] Badan Pusat Statistik, 2017. Populasi Ayam Ras Pedaging Menurut Provinsi 2009-2016. [Online] Available at: https://www.bps.go.id/linkTableDinamis/view/id/1034 [Diakses 20 November 2017].

[2] H. Riza, W. Y. R. Y., 2015. Peran Probiotik dalam Menurunkan Amonia Feses Unggas. Jurnal Peternakan Indonesia, Februari.17(1).

[3] G.J. Heiji, T. S., 1991. Studies in Environmental Science 46. Acidification Research in The Netherlands. Final Report of the Dutch Priority Programme on Acidification. 1st Edition penyunt. Amsterdam: Elsevier Science Ltd.

[4] C. W. Ritz, Dkk, 2004. Implications of Amonia Production and Emissions from Commercial Poultry Facilities: A Review. Volume 13(4), p. 684-692.

[5] Arduino, 2017. [Online] Available at: https://store.arduino.cc/usa/arduino-mega-2560-rev3 [Diakses 16 October 2017].

[6] Arlien Siswanti, S., 2016. Wireless Sensor System Untuk Pemantauan Kadar Gas Amonia (NH3) Menggunakan Algoritma Berbasis Aturan. Youngster Physics Journal, 5(2), p. 1.

[7] CANDRA, R., 2015. Rancang Bangun Sistem Pengendalian dan Monitoring Peralatan Listrik Jarak Jauh Berbasis Android. Bandar Lampung: Insitut Informatika dan Bisnis Darmajaya.

[8] Charles R.T, B. H., 1991. Pencemaran lingkungan oleh limbah peternakan dan pengelolaannya. Bull: FKG-UGM.X(2) 71-75.

[9] Eksata Murliagraha Perdana, A. M. Y. B., 2016. Rancang Bangun Pengukur Kadar Alkohol Berbasis Arduino. Jurnal Coding, 2(2), pp. 107-118 